\title{
Sustained Burning of Water-based Paint Sprays
}

\author{
PRATEEP CHATTERJEE, JOHN L. DE RIS, MOHAMMED M. KHAN and STEPHEN P. \\ D'ANIELLO \\ FM Global \\ 1151 Boston-Providence Turnpike \\ Norwood, MA 02062, USA
}

\begin{abstract}
Water-based paints used in automotive paint spray booths are prone to ignition and combustion might occur for these types of paints when finely dispersed in electrostatic spraying. An experimental study accompanied by equilibrium calculations of adiabatic stoichiometric flame temperature $\left(T_{a d}\right)$ has been conducted to investigate the burning behavior of water-based spray paints. Several spray fire tests have been carried out and the heat release rates of the flames have been measured. To compare the paints burning behavior, acetone has been added at various concentrations for the spray fire tests. The results have been compared against computed $T_{a d}$ values for the paint-acetone mixtures. Elemental compositions of the paints and their heats of combustion have been measured to compute $T_{a d}$. A critical temperature $\left(T_{a d, c r}\right)$ at which combustion will not sustain itself is proposed to characterize the water-based paints. Completeness of combustion ( $\eta_{\text {comb }}$ ) of paint-acetone mixture spray fires has also been used to evaluate the burning behavior of the paints. Based on the critical temperature and completeness of combustion, two regimes of combustion have been identified.
\end{abstract}

KEYWORDS: ignition, heat release rate, hazard evaluation, adiabatic flame temperature, fire behavior

NOMENCLATURE LISTING

$\begin{array}{llll}E_{\text {error }} & \text { Error of sum } & \dot{Q}_{c h} & \text { Chemical heat release rate }(\mathrm{kW}) \\ \Delta H_{c} & \text { Gross heat of combustion }(\mathrm{kJ} / \mathrm{kg}) & T_{a d} & \text { Adiabatic temperature }(\mathrm{K}) \\ \Delta H_{c, a} & \text { Corrected heat of combustion }(\mathrm{kJ} / \mathrm{kg}) & T_{a d, c r} & \text { Critical adiabatic temperature }(=1710 \mathrm{~K}) \\ \dot{m}_{\text {mixture }} & \text { Mass flow rate of paint mixtures }(\mathrm{kg} / \mathrm{s}) & Y_{i} & \text { Species mass fraction }\end{array}$

Greek

$\eta_{\text {comb }} \quad$ Completeness of combustion

\section{INTRODUCTION}

Water-based paints are increasingly being adopted by the automobile industry to replace organic-solvent paints in the automotive paint spray booth. Use of the paints reduces emissions of volatile organic compounds (VOCs) and several new technologies are being developed to produce these environmentally friendly paints $[1,2]$. The practice is to spray paint primer, and then a color coat followed by a clear top coat. The paint sprays are electrostatically attracted to the target (e.g. automobile part) that is grounded. One must be assured that there are no safety hazards to personnel during the painting process. Ignition and combustion might occur for these types of paints when finely dispersed during electrostatic spraying. Visible electrostatic discharges are often present in the spray booths and ignition can be triggered by discharge of an electrostatic arc from the robotic spray gun.

Krämer [3] has reviewed the safety requirements preventing ignition of sprayed materials and spraying equipment. Choi et al [4] have investigated the ignitability of liquid sprays due to electrostatic charge. Their study employed the concept of minimum ignition energy (MIE) to quantify ignition propensity of various flammable liquids. Von Pidoll et al [5] quantified a minimum charge transfer for ignition and identified the differences between various discharge types (e.g. corona, spark). Von Pidoll [6] has also applied MIE to study the ignition of liquid spray clouds by electric sparks. 
The most comprehensive study of the burning behavior of water-based spray paints was performed by von Pidoll and Krämer [7]. Known proportions of organic solvents, organic solids and water were mixed to create ternary mixtures and the flammability of these mixtures was then tested by spray fire tests. A relatively weak ignition source (Bunsen burner) was used in these studies that involved spray pressures of 2-4 bar. The authors proposed an empirical relationship for flammability limits for water-glycol mixtures that contain organic solids. The relationship says that the paint can be considered non-flammable if its water content exceeds a certain fraction by mass of its organic solvent plus a certain fraction by mass of organic solids. This result is apparently independent of the chemistry of the components and requires separation of these components. The separation of commercially available paints is no easy task. Also, paint manufacturers are reluctant to provide details for proprietary reasons. It is also difficult to accept a result that is independent of chemistry. Finally, one wishes to guarantee non-flammability of the paint independent of the method of spraying. Therefore, a scientific study has been conducted to investigate the fundamental combustion characteristics of water-based paints in terms of their inherent flame temperature as well as their ability to sustain a flame. The paints tested have different compositions, including aluminum that has a high heat of combustion. Based on the composition, the paints exhibit different burning behavior. The combustion criteria employed here are - (1) the adiabatic stoichiometric flame temperature $\left(T_{a d}\right)$, and (2) the completeness of combustion of highly atomized sprays exposed to a sizeable ignition flame source.

\section{ADIABATIC STOICHIOMETRIC FLAME TEMPERATURE COMPUTATION}

A critical condition for sustained combustion of a spray paint has been determined on the basis of whether its adiabatic stoichiometric flame temperature $\left(T_{a d}\right)$ is above or below a critical prescribed value. There have been many studies reported in literature suggesting the existence of a critical flame temperature for sustained combustion. Beyler [8] provides an excellent review on critical temperature based flammability studies. Based on a review of literature, de Ris [9] recommended a value of $1710 \mathrm{~K}$ for determining the concentration of various gaseous diluents needed to suppress a fire. In the absence of chemical inhibitors, the critical temperature is fairly insensitive to the nature of the fuel and/or oxidant for diffusion flames. The value of $1710 \mathrm{~K}$ was also used by de Ris [10] for estimating the amount of water dilution needed to prevent the sustained combustion of propylene glycol/water mixtures. In other words, if the adiabatic stoichiometric flame temperature of the chemical mixture is less than the critical temperature, self sustaining combustion is not possible.

The use of the adiabatic flame temperature for predicting flammability of hydrocarbons is also prevalent in the process industry. Britton [11] summarizes flammability prediction rules for single and mixed organic fuels in air under atmospheric conditions. The author showed that the maximum flame temperature can be approximately computed as a function of the net heat of complete combustion, $\Delta H_{c}$, and the stoichiometric ratio of oxygen to fuel, $S$. Melhem [12] has also proposed a general method for estimation of flammability envelopes for chemical mixtures based on chemical equilibrium calculations. The author developed an algorithm based on the Gibbs free energy minimization concept to determine the adiabatic flame temperature. Mashuga and Crowl [13] used a commercial code applying Gibbs free energy minimization to compute the adiabatic flame temperature of mixtures of fuel, oxygen and nitrogen. The techniques for computing the adiabatic flame temperature in the above mentioned studies involved simple sets of known hydrocarbons as reactants and were restricted by the limited choice of product species.

In a recent study, Khan et. al [14] successfully applied the critical temperature concept to evaluate the combustion characteristics of water-based hydraulic fluids of unknown chemical composition. A methodology based on Gibbs free energy minimization was developed to evaluate an adiabatic stoichiometric flame temperature, $T_{a d}$, for a diffusion flame. The input parameters required for this methodology are: (1) the elemental composition of the fluid, i.e., \% by mass of carbon, hydrogen, oxygen, nitrogen, etc. and (2) the gross heat of complete combustion per unit mass of fluid consumed, as measured in the oxygen bomb calorimeter. A criterion was proposed to identify less flammable water-based hydraulic fluids based on the adiabatic stoichiometric flame temperature computation and measurement of the chemical heat release rate from spray fire tests. In the present study, a similar methodology is applied to evaluate the flaming propensity of water-based spray paints. The NASA-CEA (Combustion Equilibrium 
and Applications) code [15] is applied as the solver for the equilibrium calculations. Water-based spray paints are composed of several elements including carbon, hydrogen, oxygen, sulfur, aluminum, etc. and the elemental compositions of these paints are determined by various techniques (ion chromatography, combustion analysis, ion selective electrode, potentiometric volumetric titration). In addition, the water content in the paints is determined by the Karl-Fischer coulometric titration method [16].

If the paint (the fuel) at $298.15 \mathrm{~K}$ and air in their stoichiometric proportion react adiabatically, the equilibrium products will be at the adiabatic temperature. If these products are then allowed to cool to $298.15 \mathrm{~K}$, at the same pressure, they will release the heat of combustion, $\Delta H_{c}$, as shown in Eq. 1.

$$
\underbrace{C_{x} H_{y} \mathrm{O}_{z} \ldots \ldots+n_{\text {ox }}\left(\mathrm{O}_{2}+3.76 \mathrm{~N}_{2}\right)}_{\operatorname{reac}_{(298.15 K)}} \rightarrow \underbrace{n_{\mathrm{CO}_{2} \mathrm{CO}_{2}+n_{\mathrm{H}_{2} \mathrm{O}} \mathrm{H}_{2} \mathrm{O}+\cdots \cdots}}_{\operatorname{prod}_{(298.15 \mathrm{~K})}}+\Delta H_{c}
$$

The calculation using the CEA code is performed in two steps. From the knowledge of the elemental composition of a given paint sample and starting with the pure atomic elements/molecules at their zero enthalpy reference state (i.e. C (graphite), $\mathrm{H}_{2}, \mathrm{O}_{2}, \mathrm{~N}_{2}, \mathrm{Br}_{2}$, etc. together with the stoichiometric air), one minimizes the Gibbs free energy of the mixture at constant pressure and temperature to produce the combustion products in their equilibrium state at $298.15 \mathrm{~K}$ (see Fig. 1a). This calculation gives the enthalpy of the combustion products at their reference state. Now, recall that the heat of combustion is defined as the difference of enthalpy between the original reactants and final combustion products at their respective reference temperature, $298.15 \mathrm{~K}$. So, one next calculates the adiabatic stoichiometric flame temperature by adding the measured heat of combustion to the products in a process at constant enthalpy and constant pressure (see Fig. 1b).

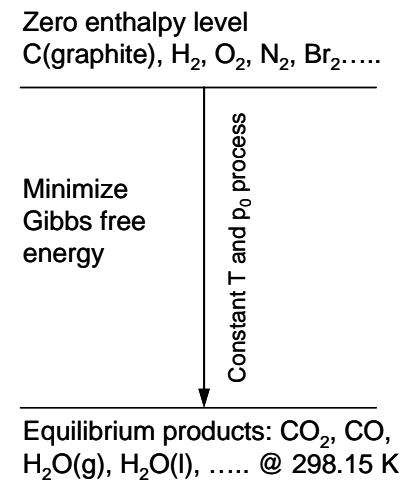

(a)

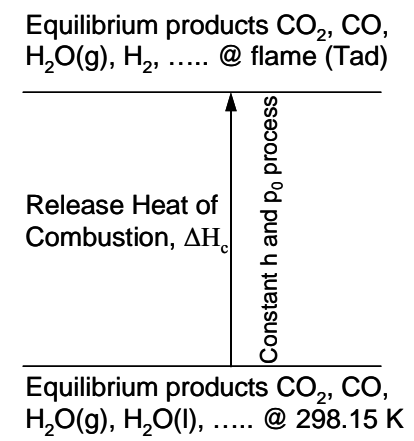

(b)

Fig. 1. Enthalpy diagram showing the two steps for $T_{a d}$ computation - (a) constant temperature $(T)$ and pressure $\left(p_{0}\right)$ process and $(\mathrm{b})$ constant enthalpy $(h)$ and pressure $\left(p_{0}\right)$ process.

\section{Validation of the Equilibrium Calculation Technique}

The technique was validated against available reference values of adiabatic flame temperatures of common hydrocarbons [17]. A further validation study was performed by comparing flame temperatures predicted for water-propylene glycol mixtures with calculations performed earlier by de Ris [10] for a propylene glycol sample and against experiments. It was predicted in the earlier study that a $56.7 \%$ by weight content of water in water-propylene glycol mixture corresponds to the critical temperature of $1710 \mathrm{~K}$. The present validation study (using elemental composition and measured heat of combustion) predicts the weight percentage of water in the mixture corresponding to the critical temperature (54.5\% water). Fig. 2 shows the comparison of the present calculations with the one conducted previously by de Ris [10]. Spray fire tests were conducted with water-propylene-glycol mixtures and it was found that the mixture with approximately $53 \%$ water did not sustain a flame [14]. The developed technique is therefore validated against experimental observation. 


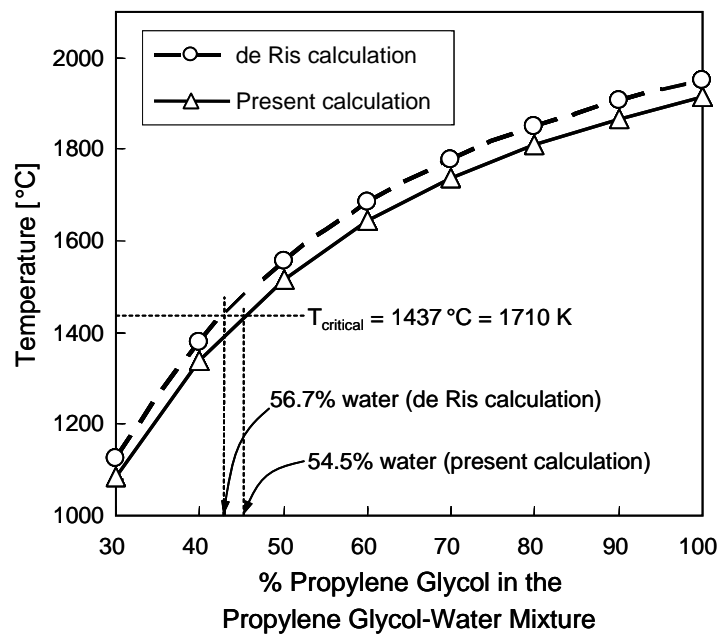

Fig. 2. Adiabatic stoichiometric flame temperature of water-propylene glycol mixtures calculated using the developed technique.

\section{Correction for Water Presence in Elemental Composition Measurements}

The elemental composition measurements include the presence of water in the samples (measured by the Karl Fischer method per ASTM D4014). The presence of water in the samples causes interference in elemental composition measurement of oxygen. Some of the Karl Fischer water content is included in the mass percent of oxygen ( $\mathrm{O}$ atom). Suppose, $Y_{i}$ is the reported mass fraction of element $i$, where $i$ can be $\mathrm{K}, \mathrm{P}, \mathrm{Ca}, \mathrm{O}, \mathrm{Br}, \mathrm{Cl}, \mathrm{F}, \mathrm{S}, \mathrm{Karl}$ Fischer water, C, H, N, etc. The sum of all the elements including Karl Fischer water $\left(Y_{W}\right)$ is:

$$
\sum_{i}=Y_{K}+Y_{P}+Y_{C a}+\ldots \ldots+Y_{W}
$$

This sum can be greater than unity. The error in the sum is $E_{\text {error }}=\sum_{i}-1$. Note that $E_{\text {error }}<Y_{W}$. This is because much of the reported oxygen and hydrogen is also included in the Karl Fischer water mass fraction. With the observation that some of the Karl Fischer water comprises of hydrogen and oxygen of the original undiluted fluid, the actual mass fractions for oxygen and hydrogen in the absence of any water are calculated as follows:

$Y_{O, a}=\frac{Y_{O}-\frac{16}{18} E_{e r r o r}}{1-Y_{W}} ;$ and $Y_{H, a}=\frac{Y_{H}-\frac{2}{18} E_{\text {error }}}{1-Y_{W}}$

The corrected actual mass fractions of each element in the absence of any water are then calculated as:

$Y_{K, a}=\frac{Y_{K}}{1-Y_{W}}, \quad Y_{P, a}=\frac{Y_{P}}{1-Y_{W}}, \quad Y_{C a, a}=\frac{Y_{C a}}{1-Y_{W}}, \cdots \cdots$

The gross heat of complete combustion per unit mass of fluid consumed ( $\Delta H_{c}$ in $\mathrm{kJ} / \mathrm{kg}$ ) is measured in the oxygen bomb calorimeter at the laboratory. The corrected gross heat of complete combustion, $\Delta H_{c, a}$ is calculated from the measured gross heat of complete combustion per unit mass of fluid consumed ( $\Delta H_{c}$ in $\mathrm{kJ} / \mathrm{kg}$ ) and the Karl Fischer water mass fraction, $Y_{W}$ : 
$\Delta H_{c, a}=\frac{\Delta H_{c}}{1-Y_{W}}$

The accuracy of the above calculation methodology can be demonstrated by comparing a paint in its concentrate form with the normal paint suitably diluted with water. The correction procedure to evaluate the actual mass fractions of elements is applied for both samples - concentrate and normal paint (paint \#2). The concentrate has $44.39 \%$ Karl Fischer water and the paint has $60.25 \%$ Karl Fischer water (\%mass). We next determine what would happen if one were to subtract the water from both concentrate and normal paint. After applying the correction, the water mass fraction is zero for both samples, the mass fraction of both oxygen and hydrogen are reduced. After correction, the elemental compositions of both concentrate and paint come into reasonable agreement (see Table 1). A good match (5\% error) is also observed for the heats of combustion. The mass fractions of elements in Table 1 have not been normalized. For normalized values of elemental mass fractions, see Table 2. Further confirmation of the accuracy of the correction technique is gained by computing the adiabatic stoichiometric flame temperatures for the corrected concentrate and paint from Table 1 . Water is added during the $T_{a d}$ computation in varying concentration $0 \%$ to $90 \%$ by mass. Fig. 3a shows the computed $T_{a d}$ values plotted against added water fraction (in \% mass). With increasing added water mass fraction, the adiabatic stoichiometric flame temperature decreases for both the concentrate and the paint. The computed temperatures for both the concentrate and paint samples show good agreement for the entire water mass fraction range.

Table 1. Comparison of elemental composition (\%mass) of paint \#2 with its concentrate.

\begin{tabular}{ccccc}
\hline Element & $\begin{array}{c}\text { Concentrate } \\
\text { analysis with KF Water }\end{array}$ & $\begin{array}{c}\text { Concentrate } \\
\text { after Correction }\end{array}$ & $\begin{array}{c}\text { Paint } \\
\text { analysis with KF Water }\end{array}$ & $\begin{array}{c}\text { Paint } \\
\text { after Correction }\end{array}$ \\
\hline Carbon & 33.18 & 59.67 & 23.51 & 59.14 \\
Oxygen & 46.63 & 12.90 & 58.79 & 13.17 \\
Hydrogen & 9.86 & 8.86 & 9.48 & 7.01 \\
Nitrogen & 1.50 & 8.86 & 1.15 & 11.32 \\
Sulfur & 0.05 & 0.09 & 0.05 & 0.13 \\
Potassium & 0.004 & 0.01 & 0.005 & 0.01 \\
Phosphorus & 0.02 & 0.03 & 0.02 & 0.05 \\
Iron & 0.005 & 0.01 & 0.005 & 0.01 \\
Silicon & 0.03 & 0.06 & 0.04 & 0.10 \\
Aluminum & 5.20 & 9.51 & 3.59 & 9.06 \\
\hline Sum total & 96.48 & 100.00 & 96.64 & 0.00 \\
\hline Water & 44.39 & 0.00 & 60.25 & 29600 \\
$\Delta H_{c}$ in $k J / k g$ & 17420 & 31330 & 11770 & \\
\hline
\end{tabular}

\section{Adiabatic Stoichiometric Flame Temperature Computation for Water-based Paints}

Unlike propylene glycol-water mixtures, some paints do not burn very efficiently in a spray flame configuration due to the presence of several trace elements like halogens. The water content in paints is also considerably higher compared to water-based hydraulic fluids. The higher water content in the paints prevents a stable flame from being sustained and therefore water presence in these paints is desirable from the flammability point of view. However, to validate the $T_{a d}$ computations for the paints, spray fire experiments were conducted by adding acetone to the paint samples in varying proportions. Acetone addition increases the heats of combustion of the mixtures and reduces the tendency for incompleteness of combustion. Acetone addition also affects the $T_{a d}$, as can be observed in Fig. $3 \mathrm{~b}: T_{a d}$ of the paints typically increases with increasing acetone mass fraction in the mixture. Four automobile paints were chosen for the validation study (see Table 2 for corrected elemental compositions of the paints). These paints differed from each other in water content, presence of metallic solid particulate matter and heats of combustion. 


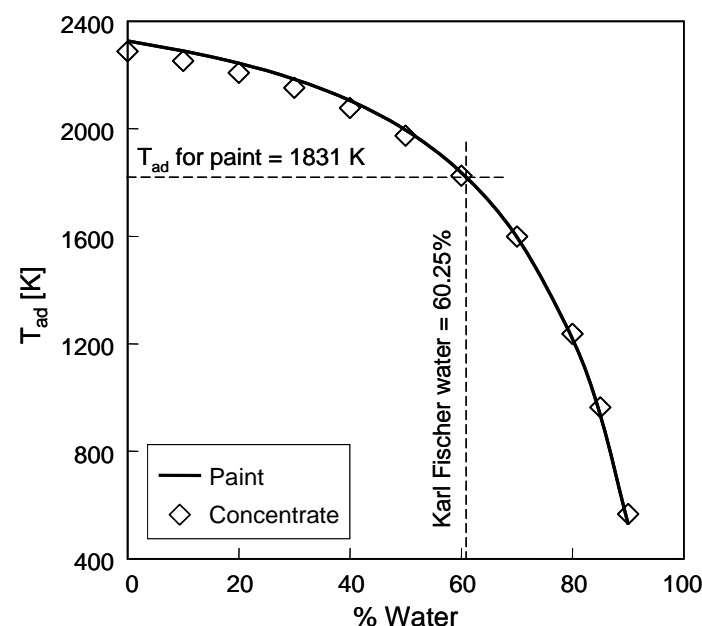

(a)

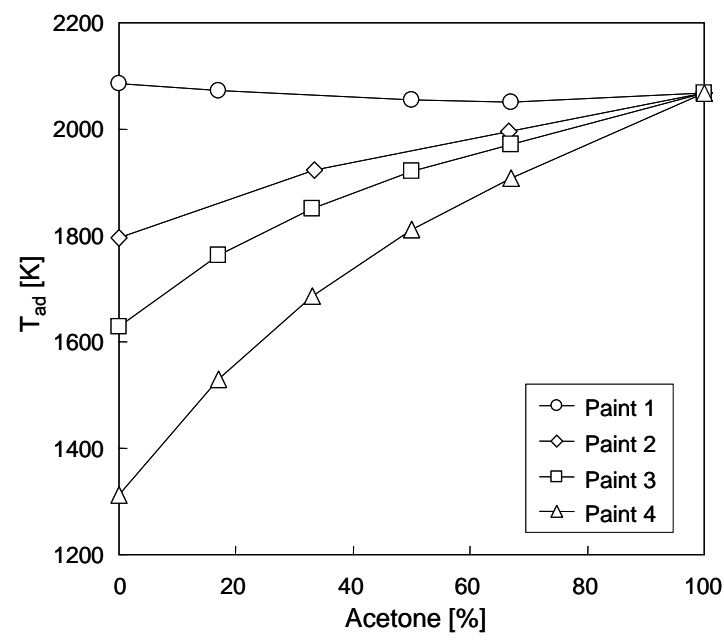

(b)

Fig. 3.(a) The effect of water addition on the computation of $T_{a d}$ for the paint and its concentrate sample,

(b) computed $T_{a d}$ of four paints chosen for the experimental study.

\section{EXPERIMENTAL INVESTIGATION}

Experiments were performed at the FM Global Research Campus under the $200 \mathrm{~kW}$ fire products collector [18] (see Fig. 4) using the apparatus developed for hydraulic fluid spray fire testing [19]. Spray tests were conducted for paints-acetone mixtures with decreasing concentrations of acetone $-67 \%$ to $8 \%$ acetone by mass. In earlier spray tests performed with paints-acetone mixtures it was observed that, for certain cases, mixing large amounts of acetone to the paint samples resulted in separation of liquid phases. Rapid sedimentation was also noticed that resulted in two different regimes of burning - the heat release rates from the flames changed throughout the duration of the tests. To ensure that acetone addition does not affect the chemical nature of the paints and that there is only minor change in the heats of combustion, a mixing study was conducted. By carefully controlling the acetone addition rate to the paints, it was determined that acetone added at a slow rate does not affect the heats of combustion of the paints. It was also determined that there is no liquid-liquid phase separation by centrifuging the acetone-paint mixtures at 15,000 RPM. Acetone up to $50 \%$ by mass added to paint does not alter the chemical nature for several hours. The centrifuging process at a very high RPM showed that acetone mass fractions over $50 \%$ can be detrimental to the chemical state of the paints. However, mixtures created by slow addition of acetone up to $67 \%$ by mass remained stable for several hours. For the spray tests, the paint-acetone mixtures were generated immediately before the experiments were conducted to make sure that there is no separation of liquid phases.

Table 2. Normalized elemental compositions (\%mass) and corrected heats of combustion.

\begin{tabular}{cccccc}
\hline Element & Acetone & Paint 1 & Paint 2 & Paint 3 & Paint 4 \\
\hline Carbon & 62.04 & 19.87 & 24.32 & 21.62 & 26.53 \\
Hydrogen & 10.41 & 10.15 & 9.81 & 10.45 & 10.92 \\
Nitrogen & 0.00 & 0.85 & 1.19 & 1.91 & 1.42 \\
Oxygen & 27.55 & 68.66 & 60.83 & 62.86 & 61.00 \\
Chlorine & 0.00 & 0.19 & 0.00 & 0.00 & 0.00 \\
Sulfur & 0.00 & 0.05 & 0.05 & 0.05 & 0.05 \\
Potassium & 0.00 & 0.02 & 0.00 & 0.00 & 0.00 \\
Phosphorus & 0.00 & 0.01 & 0.02 & 0.02 & 0.00 \\
Iron & 0.00 & 0.00 & 0.01 & 0.00 & 0.00 \\
Titanium & 0.00 & 0.02 & 0.00 & 0.01 & 0.00 \\
Silicon & 0.00 & 0.12 & 0.04 & 0.03 & 0.03 \\
Aluminum & 0.00 & 0.05 & 3.71 & 3.03 & 0.02 \\
\hline$\Delta \mathrm{H}_{\mathrm{c}}(\mathrm{kJ} / \mathrm{kg})$ & 26300 & 12560 & 11770 & 10420 & 9110 \\
\hline
\end{tabular}



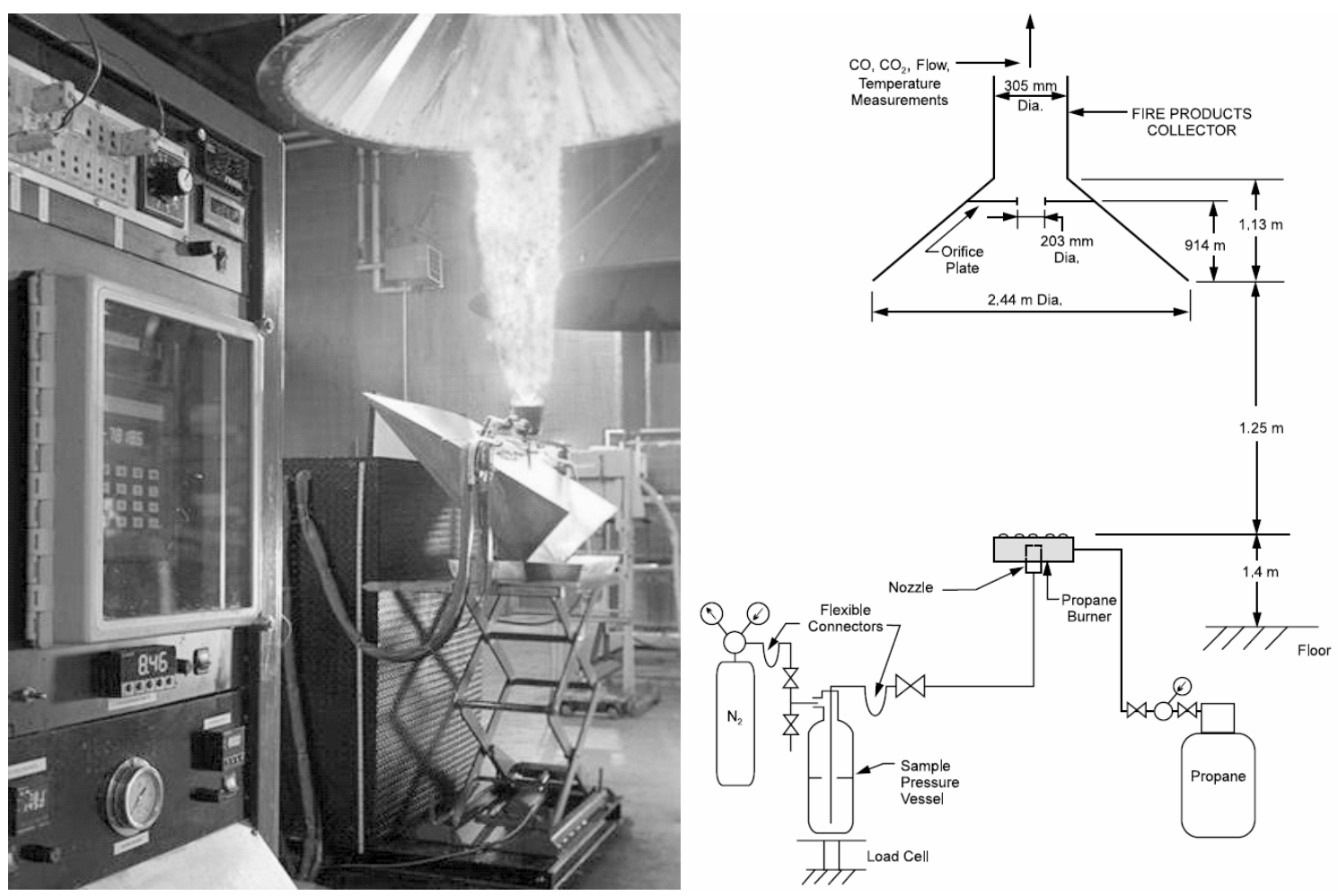

Fig. 4. Spray fire test setup under the FM Global $200 \mathrm{~kW}$ fire products collector.

The paint-acetone mixtures were sprayed from a hollow cone nozzle (exit diameter: $0.33 \mathrm{~mm}$ ) at a very high pressure, 6.9 MPa (1000 psi), to generate a fine atomized spray. Using such a nozzle with high pressure ensures a high degree of atomization so that the effect of drop size on combustion behavior (in terms of incompleteness of combustion) can be eliminated and the fluid can be assessed only on the basis of its fire resistance [19]. The chemical heat release rate, $\dot{Q}_{c h}(k W)$ is measured by the $200 \mathrm{~kW}$ calorimeter. In order to achieve ignition and to maintain the spray fire, the nozzle is surrounded by a propane ring burner $(\sim 14 \mathrm{~kW})$. A homogeneous gas mixture is created from finely atomized acetone-paint sprays by instantaneous vaporization due to the presence of the ignition source. The propane ring burner is switched on at the same time as the paint-acetone mixture spray exits from the hollow cone nozzle. This prevents the preheating of the paint-acetone mixture. The tests were typically conducted for durations of $300-400 \mathrm{~s}$.

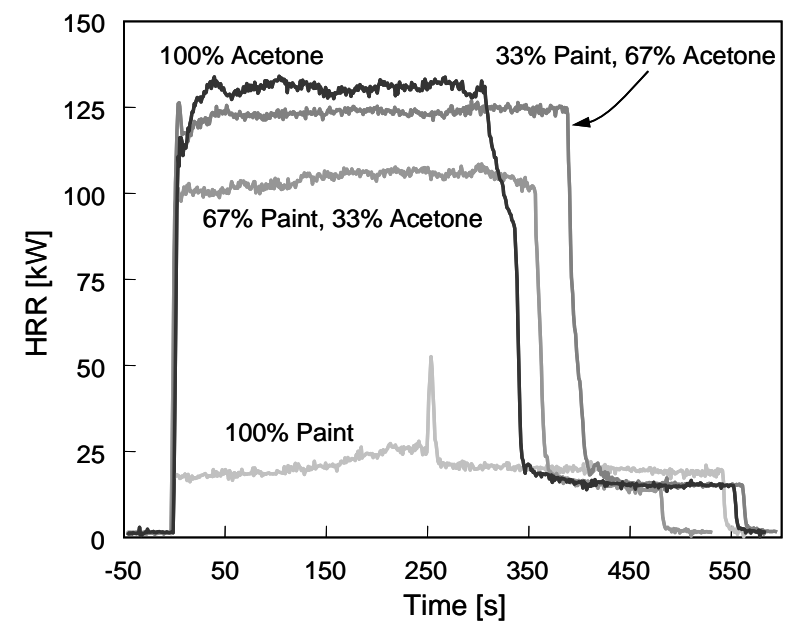

Fig. 5. Heat release rates for paint $\# 2$ spray fire tests. The propane burner contributes $\sim 14 \mathrm{~kW}$. 
Fig. 5 shows the temporal variation of heat release rates for paint $\# 2$-acetone mixtures. The mean heat release rate is highest for pure acetone burning and is reduced as the paint mass fraction in the mixtures increases. The spike observed $200 \mathrm{~s}$ after ignition for the pure paint spray was caused by a momentary increase in flame height with sparks, likely due to burning of aluminum particles present in the paint (3.71\% by mass). Paint \#2 flames were steady with the flame height decreasing with decreasing acetone mass fraction. This was also the case for paint \#3 flames which had a similar elemental composition as paint \#2, but lower heat of combustion. Fig. 6 shows the instantaneous snapshots of flame shapes for paint $\# 3$-acetone mixtures. The flame was not sustained for the $92 \%$ paint mass fraction mixture; however a steady flame was observed for $83 \%-33 \%$ paint mass fraction mixtures. It should be noted in Fig. 6 that flame height increases with decreasing paint mass fraction in the mixtures. Paint \#4 mixture flames also exhibited similar behavior as paint \#3, but their flame heights were comparatively lower for each paint mass fraction case. This was because paint \#4 has the lowest heat of combustion $(9110 \mathrm{~kJ} / \mathrm{kg})$.

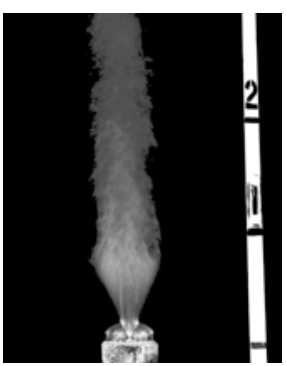

(a)

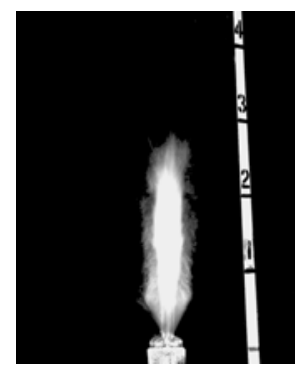

(b)

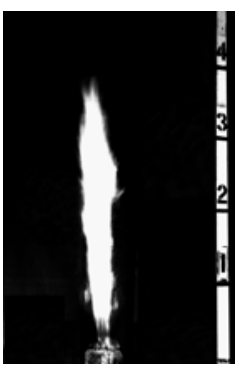

(c)

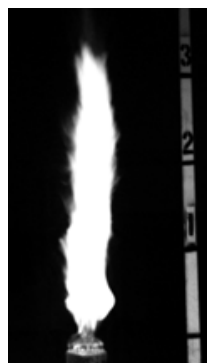

(d)

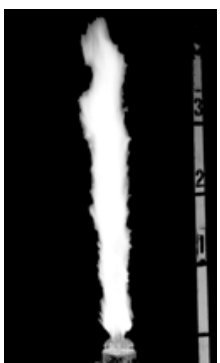

(e)

Fig. 6. Instantaneous snapshots of paint \#3 spray flames. Paint fraction - (a) $92 \%$, (b) $83 \%$, (c) $67 \%$, (d) $50 \%$ and (e) $33 \%$.

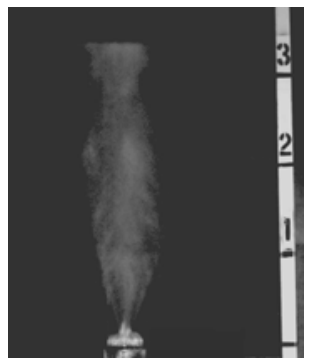

(a)

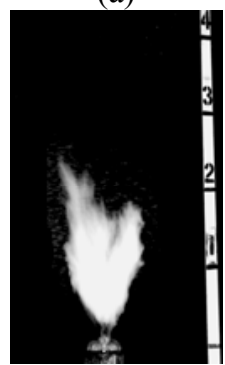

(c)
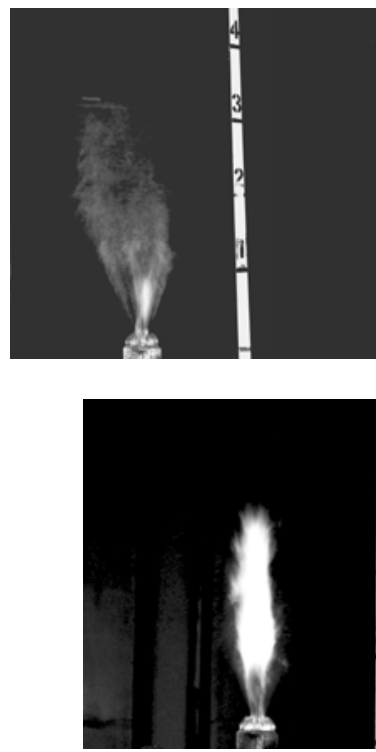

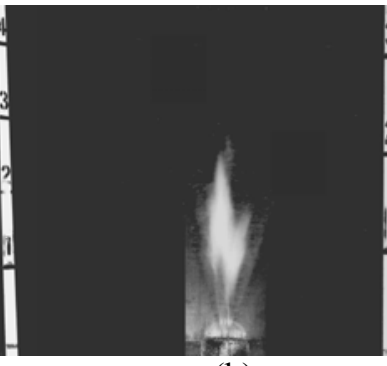

(b)
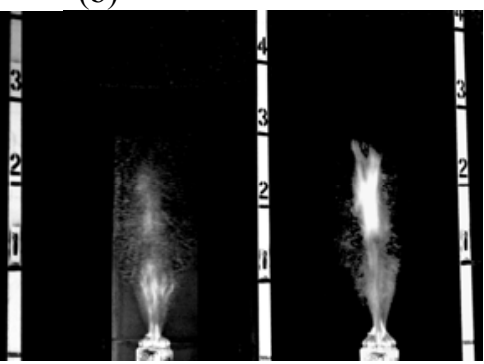

(d)

Fig. 7. Instantaneous snapshots of paint \#1 spray flames with various acetone mass fractions. Paint fraction in the test - (a) $92 \%$, (b) $83 \%$, (c) $33 \%$, and (d) $67 \%$.

The burning behaviors of paint \#1 mixtures were different from the other paint-acetone combinations. Paint \#1 mixtures showed erratic unsteady burning characteristics for higher paint mass fractions. The flame was not sustained for the $92 \%$ paint mass fraction mixture (see Fig. 7a), however at the lowest paint mass fraction (33\%), the flame was sustained. But, unlike paints \#2-4, the flame shape was very compact in this case (see Fig. $7 \mathrm{c}$ ) and the heat release rate continued to rise with time. For the $83 \%$ paint mass fraction mixture, the flame was initially not sustained but ignition occurred at an intermediate time followed by extinguishment. These phenomena can be observed in Fig. $7 \mathrm{~b}$. On the other hand, for the $67 \%$ paint mass fraction mixture, the flame was sustained at the beginning of the experiment, but extinguishment occurred 
at a later time. Re-ignition also occurred following extinguishment repeatedly resulting in an oscillating heat release rate over the duration of the test (see Fig. 7d). The peculiar combustion characteristics of paint \#1 can be attributed to the presence of potassium and halogens, in particular chlorine, acting as fire suppressants. Chlorine tries to extinguish the flame but the spray is re-ignited because of its high heat of combustion $(12560 \mathrm{~kJ} / \mathrm{kg})$ and high adiabatic flame temperature. If we compare the heat release rates for the four sets of paint-acetone tests (see Fig. 8), we can establish that paints \#1, 2 and 3 (see Fig. 8a,b,c) exhibit similar characteristics - their heat release rates decrease smoothly with increasing paint mass fraction. The mean heat release rates for paint $\# 1$ are unreliable, since the paint $\# 1$ spray tests were erratic in nature. The unsteadiness can be observed in the large spreads from mean heat release rates in Fig. 8a. In the case of paint \#4 mixtures (see Fig. 8d), the mean heat release rates exhibit a slightly different characteristic - the heat release rate initially does not change significantly, but suddenly drops for the $83 \%$ paint mass fraction mixture. The flame for this case becomes very unsteady unlike the lower paint mass fraction sprays.

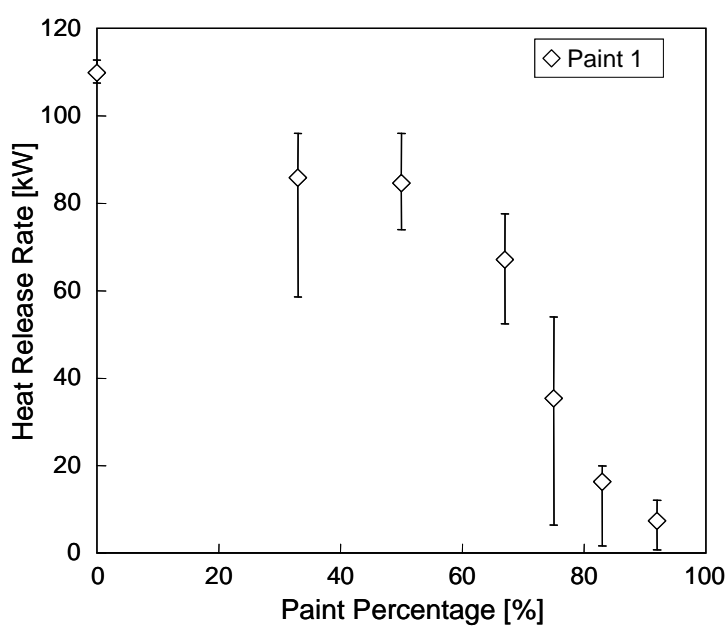

(a)

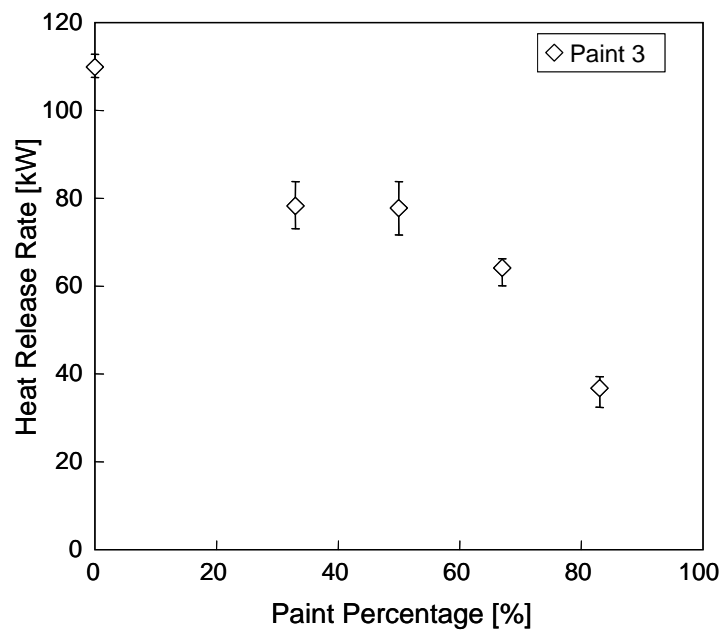

(c)

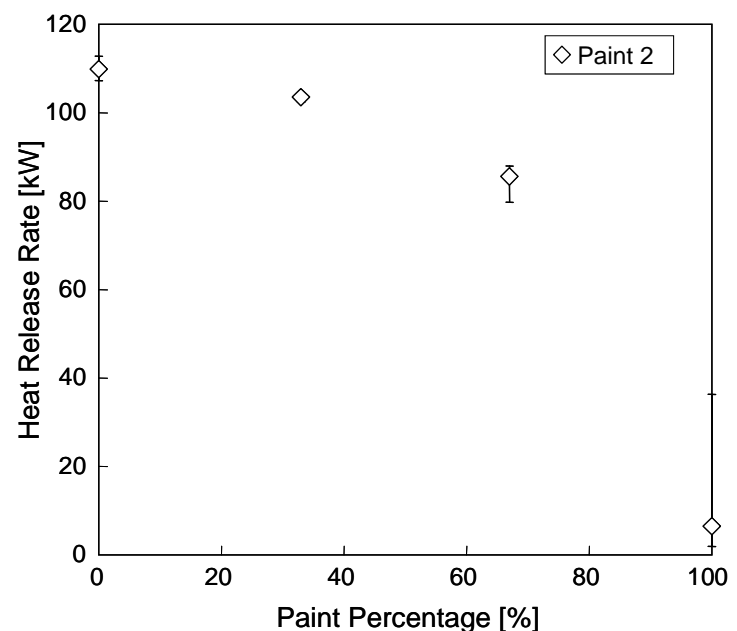

(b)

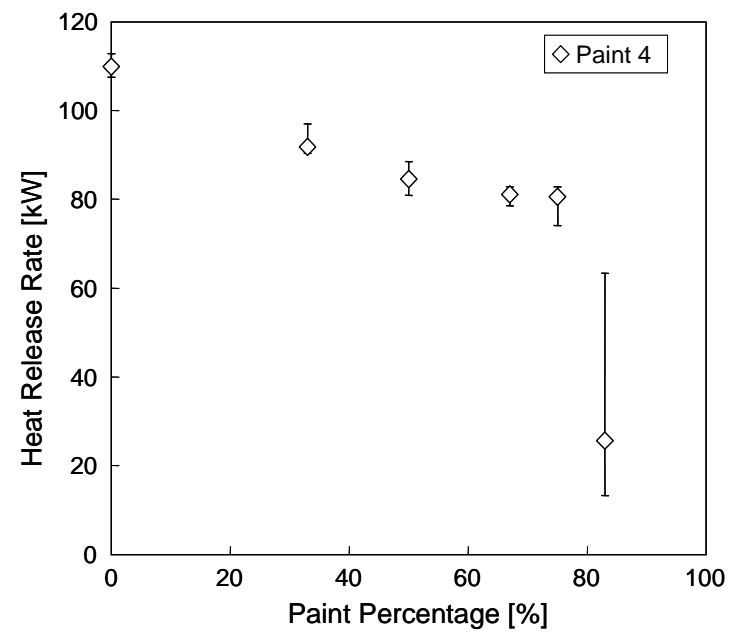

(d)

Fig. 8. Mean value of heat release rate for the paints - (a) paint \#1, (b) paint \#2, (c) paint \#3 and (d) paint \#4. The error bars represent the spread in the data. 
Comparing computed $T_{a d}$ with completeness of combustion provides us insights into the combustion characteristics of the paints. Completeness of combustion is computed from the spray tests:

$\eta_{\text {comb }}=\frac{\dot{Q}_{c h} / \dot{m}_{\text {mixture }}}{\Delta H_{c}}$

where, $\dot{Q}_{c h}$ is the chemical heat release rate measured at the calorimeter and $\dot{m}_{\text {mixture }}$ is the mass flow rate of the paint mixture flowing through the spray nozzle measured by a load cell (shown in Fig. 4). Fig. 9 shows the variation of computed $T_{a d}$ with $\eta_{c o m b}$. We avoid conducting spray fire tests for pure paint samples (these paints adversely affect the instrumentation). Two regimes of combustion are proposed, based on $T_{a d}$ computation and experimental data from acetone-paint mixture spray tests (see Fig. 9).

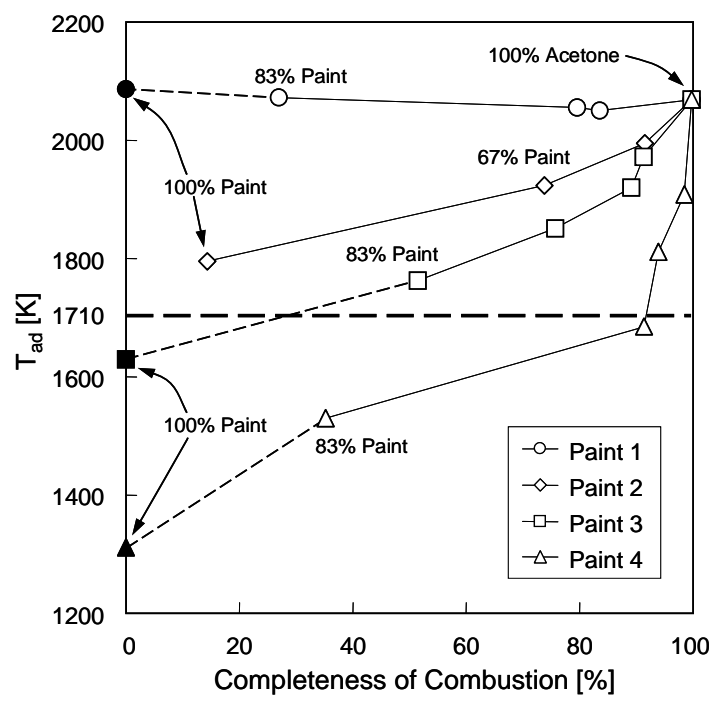

Fig. 9. Computed $T_{a d}$ plotted against $\eta_{c o m b}$ from spray tests. Acetone mass fraction for each data point can be obtained from Fig. 3(b).

The two regimes of burning for spray paints are described below:

1. $T_{a d} \leq 1710 \mathrm{~K}$ (Regime 1)

It is clear from Fig. 9 that paints \#3 and 4 fall under the first regime - their $T_{a d}$ are lower than $1710 \mathrm{~K}$ for mixtures with higher than $83 \%$ paint mass fractions. The dashed lines from the $83 \%$ paint mass fraction data points indicate an extension from the spray test results to the computed $T_{a d}$. The computed $T_{a d}$ for pure paints is shown by solid symbols (spray tests were not conducted for these data points). Since their curves pass through the $1710 \mathrm{~K}$ dashed horizontal line in Fig. 9, we establish that paints \#3 and 4 will not sustain a flame even in the presence of a strong ignition source (see Fig. $3 \mathrm{~b}$ and its discussion for details).

2. $T_{a d}>1710 \mathrm{~K}$ (Regime 2$)$

Paint \#1 belongs in the second regime - because of its high $T_{a d}$, this paint is categorized as a high risk material. In other circumstances, where the combustion is given long residence times or stronger ignition sources, the presence of fire retardants (like halogens) acting in the gas-phase would no longer be effective and could lead to significant heat release rates. Despite the fact that paint \#1-acetone mixture with $83 \%$ paint mass fraction may not burn, a flame may sustain in presence of strong ignition sources, such as high energy electric arcs. Paint \#2 is clearly the most hazardous in the set of paints tested. Although a very weak flame is sustained for the pure paint 
spray test, $T_{a d}$ for this flame is higher than $1710 \mathrm{~K}$. The paint is categorized as a flammable liquid and adequate protection needs to be taken in the automobile body painting shop while using this paint.

In summary, paints with data curves passing through the $1710 \mathrm{~K}$ dashed horizontal line in Fig. 9 are categorized as non-flammable.

\section{CONCLUSIONS AND RECOMMENDATIONS}

Adiabatic stoichiometric flame temperature computation and measured completeness of combustion from spray fire tests were used as parameters to assess the flaming propensity of four water-based spray paints. Several other paint samples were used in the earlier part of the study to decide on the final set of paints selected for this study. The four paints selected are representative of the many paints we evaluated. Two combustion regimes based on $T_{a d}$ have been identified for water-based spray paints. Table 3 summarizes the observations from the present study.

Table 3. Summary of observations for the four paints: $T_{a d}$ and burning behavior

\begin{tabular}{|c|c|c|c|c|}
\hline & Paint 1 & Paint 2 & Paint 3 & Paint 4 \\
\hline$T_{a d}$ & $\operatorname{High}(>>1710 \mathrm{~K})$ & Medium $(>1710 K)$ & Low $(<1710 K)$ & Low $(<1710 K)$ \\
\hline $\begin{array}{l}\text { Burning } \\
\text { behavior }\end{array}$ & Erratic flame $^{\mathrm{a}}$ & Steady burning ${ }^{\mathrm{b}}$ & Steady burning & Steady burning \\
\hline
\end{tabular}

${ }^{\mathrm{a}}$ Halogen flame retardant present in the paint. Flame retardants are generally less effective at large scale.

${ }^{\mathrm{b}} 100 \%$ pure paint burns.

Two paints (\#3 and 4) were categorized as non-flammable (regime 1), one paint (\#2) was found to be flammable (regime 2) and a fourth paint (\#1) was found to have moderate risk of fire (regime 2). Burning behavior of water-based spray paints can be ascertained by computing their $T_{a d}$. However, $T_{a d}$ alone cannot be the sole measure of burning propensity for water-based spray paints. It is recommended that completeness of combustion ( $\eta_{\text {comb }}$ ) be used as a second parameter to assess flammability in conjunction with $T_{a d}$.

\section{ACKNOWLEDGEMENTS}

The authors would like to thank Drs. Robert Bill, Sergey Dorofeev, Francesco Tamanini and Louis Gritzo for reviewing the manuscript. We would also like to thank Dr. Archie Tewarson for his help in identifying the equilibrium products of paint combustion. The spray fire tests were conducted by Michael Skidmore with help from Jason Tucker, Michael Gravel and Blair Swinnerton. Their contribution is acknowledged.

\section{REFERENCES}

[1] Mapleston, P. "Paint systems focus on costs, 'green' concerns", Modern Plastics, published by McGraw-Hill, October 1994, pp. 54-57.

[2] Malenfant, N. "Reducing contaminated wastewater from water-based paint", National Renewable Energy Laboratory, U.S. Department of Energy Report DOE/CH10093-223 DE93017063, 1994.

[3] Krämer, H., (1993) Safety aspects of electrostatic paint, powder and flock spraying processes, Journal of Electrostatics, 30: 77-92, http://dx.doi.org/10.1016/0304-3886(93)90064-E

[4] Choi, K. S., Yamaguma, M. and Ohsawa, A., (2007) Ignitability of sprayed liquids due to an electrostatic spark, Advanced Powder Technologies, 18(1): 105-115, http://dx.doi.org/10.1163/156855207779768115 
[5] von Pidoll, U., Brzostek, E. and Froechtenigt, H.-R., (2004) Determining the incendivity of electrostatic discharges without explosive gas mixtures, IEEE Transactions on Industry Applications, 40(6): 1467-1475, http://dx.doi.org/10.1109/TIA.2004.836303

[6] von Pidoll, U., (2001) The ignition of clouds of sprays, powders and fibers by flames and electric sparks, Journal of Loss Prevention in the Process Industries, 14(2): 103-109, http://dx.doi.org/10.1016/S0950-4230(00)00035-8

[7] von Pidoll, U. and Krämer, H., (1997) Flammability characteristics of sprays of water-based paints, Fire Safety Journal, 29: 27-39, http://dx.doi.org/10.1016/S0379-7112(97)00002-7

[8] Beyler, C., (2005) A brief history of the prediction of flame extinction based upon flame temperature, Fire and Materials, 29: 425-427, http://dx.doi.org/10.1002/fam.902

[9] de Ris, J. L., "Extinguishment of Fires by Total Flooding with Chemically Inert Gases", FM Global Technical Report Number FMRC J.I. 0W1E1.RC, Norwood, MA, 1993

[10] de Ris, J. L., private communication

[11] Britton, L. G., (2002) Using Heats of Oxidation to Evaluate Flammability Hazards, Process Safety Progress, 21(1): 31-54, http://dx.doi.org/10.1002/prs.680210108

[12] Melhem, G. A., (1997) A Detailed Method for Estimating Mixture Flammability Limits Using Chemical Equilibrium, Process Safety Progress, 16(4): 203-218, http://dx.doi.org/10.1002/prs.680160403

[13] Mashuga, C. V. and Crowl, D. A., "Flammability Zone Prediction Using Calculated Adiabatic Flame Temperatures", Process Safety Progress, 18(3):127-134, 1999

[14] Khan, M. M., Chatterjee, P. and de Ris, J. L., "Parameters to Assess the Flammability of WaterBased Hydraulic Fluids", Proceedings of the 11th Fire Science and Engineering Conference (INTERFLAM 2007), 2007, pp 113-122

[15] Gordon, S. and McBride, B. J., "Computer Program for Calculation of Complex Chemical Equilibrium Compositions and Applications - I. Analysis", NASA Reference Publication 1311, 1994

[16] http://en.wikipedia.org/wiki/Karl_Fischer_titration

[17] Turns, S. R., An Introduction to Combustion - Concepts and Applications, 2nd Ed., McGraw Hill, 2000, p. 649.

[18] Heskestad, G. "A fire products collector for calorimetry into the MW range", FM Global Technical Report, J.I. OC2E1.RA, Norwood, MA, 1981

[19] Khan, M. M., "Spray Flammability of Hydraulic Fluids, Fire Resistance of Industrial Fluids", ASTM STP 1284, G. E. Totten and J. Reichel, (Eds.), American Society for Testing and Materials, Philadelphia, 1996, p. 133. 